\title{
Introduction of a Renal Papillary Grading System for Patients with Nephrolithiasis
}

\author{
Michael Seth Borofsky, MD \\ Department of Urology, Indiana University School of Medicine, Indianapolis, Indiana. \\ Jessica E. Paonessa, MD \\ Department of Urology, Indiana University School of Medicine, Indianapolis, Indiana.
}

\section{Andrew P. Evan, PhD}

Department of Anatomy and Cell Biology, Indiana University School of Medicine, Indianapolis, Indiana.

\section{James C. Williams, PhD}

Department of Anatomy and Cell Biology, Indiana University School of Medicine, Indianapolis, Indiana.

Fredric L. Coe, MD

Section of Nephrology, The University of Chicago, Chicago, Illinois.

Elaine M. Worcester, MD

Section of Nephrology, The University of Chicago, Chicago, Illinois.

James E. Lingeman, MD, FACS

Department of Urology, Indiana University School of Medicine, Indianapolis, Indiana.

E-mail: jlingeman@iuhealth.org

(c) Mary Ann Liebert, Inc. DOI: 10.1089/vid.2015.0023
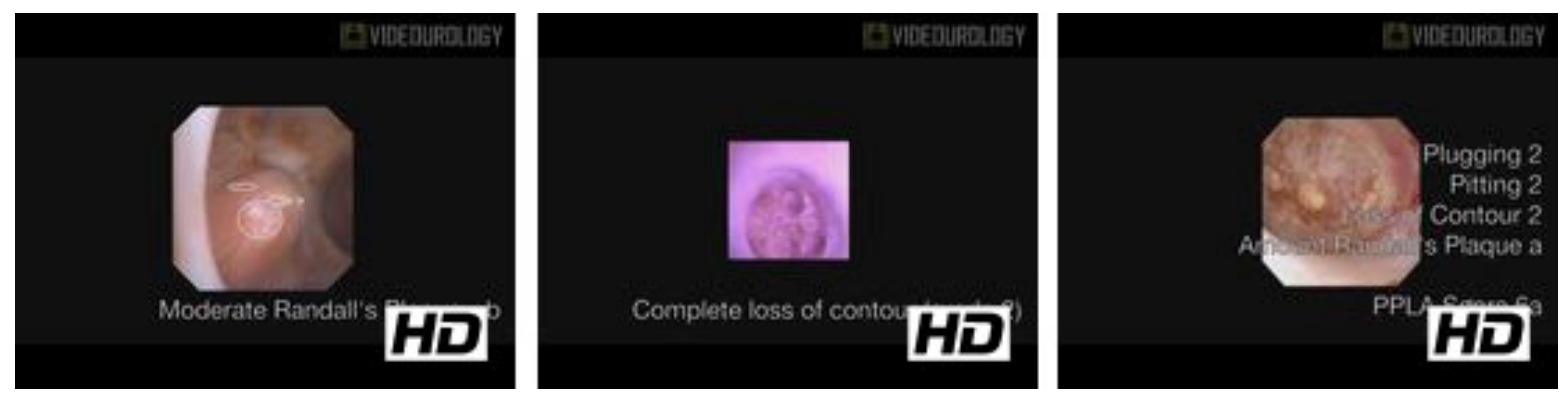

\section{Abstract:}

Introduction: An overlooked finding at the time of renal endoscopy for patients with nephrolithiasis is the appearance of the renal papillae. Recent work has demonstrated that it is possible to distinguish specific stone-forming phenotypes by endoscopic patterns of papillary appearance alone. ${ }^{1-4}$ These variable expressions are likely to have clinical significance; yet, the ability to pursue such research efforts remains limited by the lack of a standardized system to describe these findings. Herein, we describe a novel grading system designed to standardize and simplify the description of renal papillary appearance in stone formers at the time of endoscopy.

Materials and Methods: Since 1999, 342 patients have been prospectively enrolled and given consent to be part of an $\mathrm{NIH}$ funded project studying the pathogenesis of stone formation at a single institution (Methodist Hospital, Indiana University Health). Patients have been treated and studied using both percutaneous and retrograde ureteroscopic approaches. Digital scopes are utilized when feasible along with fluoroscopy to map the affected renal unit(s), and stones are removed and analyzed individually when possible. ${ }^{5}$ 
Results: Four recurring abnormal papillary features were identified based upon the collective knowledge and expertise of the primary research team. Each variable was then quantitated based on the severity in appearance. Three features believed to be associated with papillary injury include ductal plugging, pitting, and loss of papillary contour. Ductal plugging is evident as either suburothelial deposits of yellow mineral or as dilated ducts of Bellini, presumably left behind after a plug has passed. These two subfeatures are considered the same for the purposes of grading. Pitting reflects crater-like erosion of the papillary surface. Loss of contour reflects global depression of the papilla relative to the surrounding tissue. Upon papillary inspection, each papilla receives a numerical grade from 0 to 2 for each of these measured domains. The three scores are then added together to create a sum total score regarding the degree of papillary injury ranging from 0 to 6 . The fourth feature, the amount of Randall's plaque, is evident as white deposits along the papillary surface. It is not known to cause papillary injury ${ }^{6}$ and, as such, is designated with an alphabetical subscore $(a-c)$ rather than a number. Each papilla then receives a final unique score incorporating both the sum numerical and alphabetical grade. Reference examples are shown in the accompanying video.

Conclusions: The creation of a standardized system to describe the papillary appearance in stone formers has considerable clinical and academic utility. On a clinical level, it could be applied as a tool to document intraoperative findings and determine changes in papillary appearance over time in recurrent stone formers. It also has the potential to distinguish high-risk patients with more pressing needs of metabolic evaluations, medical therapy, and surveillance imaging. As a research tool, it would help create a common language to describe papillary appearance and improve collaboration between researchers. It also might allow surgeons to better correlate endoscopic findings to pathological findings and clinical outcomes such as stone analysis, associated metabolic diseases, risk of progressive renal injury, and stone recurrence.

No competing financial interests exist. Accompanying manuscript submitted to Journal of Endourology (END-2015-0298; in review).

Runtime of video: 5 mins 37 secs

\section{Cite this video}

Michael Seth Borofsky, Jessica E. Paonessa, Andrew P. Evan, James C. Williams, Fredric L. Coe, Elaine M. Worcester, James E. Lingeman, Introduction of a Renal Papillary Grading System for Patients with Nephrolithiasis, J Endourol Part B Videourology. 2015, DOI: 10.1089/vid.2015.0023.

\section{References}

1. Evan AP, Lingeman J, Coe F, et al. Renal histopathology of stone-forming patients with distal renal tubular acidosis. Kidney Int 2007;71:795-801.

2. Matlaga BR, Williams JC, Jr., Kim SC, et al. Endoscopic evidence of calculus attachment to Randall's plaque. J Urol 2006;175:1720-1724; discussion 1724.

3. Miller NL, Williams JC, Jr., Evan AP, et al. In idiopathic calcium oxalate stone-formers, unattached stones show evidence of having originated as attached stones on Randall's plaque. BJU Int 2010;105:242-245.

4. Coe FL, Evan AP, Worcester EM, Lingeman JE. Three pathways for human kidney stone formation. Urol Res 2010;38:147-160.

5. Kuo RL, Lingeman JE, Evan AP, et al. Endoscopic renal papillary biopsies: A tissue retrieval technique for histological studies in patients with nephrolithiasis. J Urol 2003;170(6 Pt 1):2186-2189.

6. Evan AP, Lingeman JE, Coe FL, et al. Randall's plaque of patients with nephrolithiasis begins in basement membranes of thin loops of Henle. J Clin Invest 2003;111:607-616.

Original Publication Date: 2015 